\title{
Mother's Satisfaction towards Childbirth Care at Public Health Centers in Bench-Maji Zone, Ethiopia: A Facility-Based Cross- Sectional Study
}

\author{
Shewangizaw Hailemariam ${ }^{D},{ }^{1}$ Amare Genetu ${ }^{D},{ }^{1}$ and Ermiyas Sahile ${ }^{2}$ \\ ${ }^{1}$ Department of Midwifery, College of Health Science, Mizan-Tepi University, Mizan-Teferi, Ethiopia \\ ${ }^{2}$ Department of Midwifery, College of Health Science, Kotebe Metropolitan University, Addis Ababa, Ethiopia \\ Correspondence should be addressed to Shewangizaw Hailemariam; shewa1278@gmail.com
}

Received 21 February 2020; Revised 1 June 2020; Accepted 16 June 2020; Published 3 July 2020

Academic Editor: Hind A. Beydoun

Copyright (c) 2020 Shewangizaw Hailemariam et al. This is an open access article distributed under the Creative Commons Attribution License, which permits unrestricted use, distribution, and reproduction in any medium, provided the original work is properly cited.

\begin{abstract}
Background. Assessing the level of maternal satisfaction towards maternal health care services has a paramount importance in improving the service quality and enhancing service utilization. Hence, the aim of this study was to assess maternal satisfaction towards childbirth care and its determinants at public health facilities in Bench-Maji Zone, Ethiopia. Methods. A facility-based cross-sectional study was conducted from May 20, 2018, to July 11, 2018 in Bench-Maji Zone, Ethiopia. A total of 845 mothers were selected by employing a systematic random sampling technique. Data were collected using a pretested and structured questionnaire. Satisfaction was measured by the five-point Likert scale from very dissatisfied (1) to very satisfied (5). Data were entered in to Epi data version 3.1 and analyzed using SPSS version 20. A $P$ value $<0.05$ was considered to declare statistical significance. Result. About 506 (63.25\%) of the mothers were satisfied by the overall care provided during childbirth. Factors associated with mothers' satisfaction with childbirth care includes attending no formal education $[\mathrm{AOR}=3.69 ; 95 \% \mathrm{CI}(1.99,7.91)]$, rural residency $[\mathrm{AOR}=2.63 ; 95 \% \mathrm{CI}(1.43,5.80)]$, perceived measure taken to assure privacy $[\mathrm{AOR}=3.56 ; 95 \% \mathrm{CI}(1.25,7.41)]$, and attending antenatal care $[\mathrm{AOR}=6.23 ; 95 \% \mathrm{CI}(3.42,12.87)]$. Conclusion. The overall satisfaction of mothers with childbirth care in public health centers of Bench-Maji Zone is low when compared with other studies. Hence, understanding mothers' expectations, assuring privacy, and enhancing antenatal care attendance might improve maternal satisfaction with childbirth care.
\end{abstract}

\section{Background}

Mothers' satisfaction with childbirth care is a multidimensional construct comprising satisfaction with technical aspects, environmental aspects, and communication and interpersonal aspects [1]. The assessment of mothers' satisfaction adds an important "consumer" perspective to evaluations. Feedback from mothers can influence the whole quality improvement agenda within the institution or organization [2]. Mothers who perceive the quality of care as good, are more likely to visit it again, thereby increasing demand for the service $[3,4]$. Maternal health service utilization and neonatal outcome can be considerably enhanced by improving the quality of facility childbirth care.
Globally, low-middle-income countries continue to account for almost all of the pregnancy-related mortalities that are largely preventable through adequate utilization of essential maternal health care services such as skilled birth assistance (SBA) and antenatal care (ANC) [5]. Studies suggest that utilization of SBA and ANC is highly influenced by mothers' satisfaction [6]. Hence, the World Health Organization (WHO) recommend mothers' service satisfaction be assessed to improve the quality and effectiveness of health care [7].

It is a well-established fact that maternal satisfaction on the provided service could enhance subsequent utilization and compliance with medical treatments [8-10]. However, there is a limited study regarding the extent of mothers' satisfaction with delivery service in Ethiopia. Hence, this study 
will provide evidence regarding mothers' satisfaction with childbirth care and its determinants.

\section{Methods}

2.1. Study Area and Design. Facility-based cross-sectional study was conducted from May 20 to July 11, 2018, in Bench-Maji Zone which is located $561 \mathrm{~km}$ away from Addis Ababa, the capital city of Ethiopia, in Southwest direction with an estimated population of 829,493 out of which 418,213 are women; 129,500 are children under five; and 26,462 are under 1 year. The zone has 39 functional public health centers. Additionally, there are 182 functional health posts and 9 under construction, one university, and one health science college. The zone has 182 midwives, 329 nurses, and 476 health extension workers [11].

2.2. Source and Study Population. Source population were all mothers who gave birth in public health centers of BenchMaji Zone, and the study population were all mothers who gave birth in selected public health centers of Bench-Maji Zone from May 20, 2018, to July 11, 2018.

2.3. Sample Size and Sampling Procedure. During the calculation of the sample size, the proportion of mothers satisfied with delivery service in Bench-Maji Zone was assumed to be $50 \%$. Based on the assumption that the actual sample size for the study was determined using a single-population proportion formula with a marginal error of $5 \%$ and $95 \%$ confidence level, the sample size became 384. Considering design effect, the sample size was multiplied by 2 and a $10 \%$ nonresponse rate was added and the final sample size became 845 .

A two-stage sampling technique was employed to select study participants. At the first stage, twelve public health centers ( $30 \%$ of the public health centers) were selected from a total of 40 public health centers found in Bench-Maji Zone. Second, the total sample size was proportionally allocated to each of the selected public health centers based on the average number of delivery in the most recent quarterly report of each health centers. Finally, after calculating " $K$ ” for each public health centers, the study participants were selected by using a systematic random sampling technique.

2.4. Data Collection Tool and Procedure. Exit interview was made by using a structured tool having four sections: the first section contains sociodemographic characteristics of the mother, the second section contains obstetric characteristics of the mother, the third was about mother's perception of health care service, and the forth section contains satisfactionrelated questions. Client satisfaction measuring instrument was adapted from Ethiopian Ministry of Health and contextualized to labor and delivery setting. The satisfaction items were grouped into three categories: technical aspects, environmental aspects, and communication and interpersonal aspects. Each components of satisfaction were measured by 6 items. Overall mothers' satisfaction was measured by 18 items each having a five-point Likert scale from very dissatisfied (1) to very satisfied (5). The overall satisfaction scale had an internal consistency or reliability score of 0.83 . Data were collected by twelve midwives after having 3 days of training about the data collection process and the purpose of the study. During data collection, the data was checked for completeness and consistency of information. The overall data collection process was supervised by three public health officers. The local language Amharic was used to collect the data.

2.5. Operational Definition. Client overall satisfaction and component-wise client satisfaction were dichotomized into satisfied and dissatisfied depending on the threshold which was computed using the demarcation threshold formula: $(($ total highest score - total lowest score $) / 2)+$ total lowest score [10].

2.6. Data Processing and Analysis. Data were checked for completeness, edited, cleaned, coded, and entered in to EpiData version 3.1 and then was exported to SPSS version 20 for analysis. In the descriptive statistics, frequencies, proportion, and mean was calculated and the results of the analysis were presented in text and tables. Binary logistic regression was carried out to assess the association of different independent variables with the dependent variable. Independent variables having $P<0.25$ on the binary logistic regression analysis were considered candidates for the final multivariate logistic regression analysis. Multivariate logistic regression analysis was carried out to identify factors having statistically significant associations with mothers' overall satisfaction with childbirth care.

2.7. Data Quality Assurance. The questionnaire prepared in English was translated into Amharic and then back translated into English to ensure consistency. The questionnaire was pretested on $5 \%$ of the actual sample size in Maji district. There was supervision on a daily basis and checking on $10 \%$ of the collected questionnaire. Finally, error reports were checked after entry to EpiData using each case code.

2.8. Ethical Consideration. Ethical clearance was obtained from Mizan-Tepi University. Permission was also obtained from Bench-Maji zone Health department and health centers as well. Efforts were made to keep confidentiality of the data; all participants were reassured that no personal identifier will be used. Verbal informed consent was sought from all study participants.

\section{Result}

3.1. Sociodemographic Characteristics of the Respondents'. A total of $94.7 \%, n=800$, mothers willingly responded to the interviewer-administered structured questionnaire. The mean age of the respondents' was $24.7( \pm 3.26)$ years. The minimum and the maximum age of the respondents' were 18 and 39, respectively. Of the total respondents, 404 (50.5\%) had no formal education and 344 (43\%) were housewives. The majority $729(91.1 \%)$ of respondents were married, over $330(41.25 \%)$ of respondents were Protestant Christians, and 305 (38\%) of the respondents were Orthodox Christians. Twenty-six percent of the respondents reside in urban areas (Table 1).

3.2. Obstetrics and Other Maternal Factors. Regarding obstetrics characteristics, 723 (90.4\%) had antenatal care follow-up, 
TABLE 1: The sociodemographic characteristics of mothers who gave birth in selected public health centers of Bench-Maji Zone, Ethiopia. May 2018. $n=800$.

\begin{tabular}{|c|c|c|c|c|}
\hline Variable & Response & Frequency & Percentage & $P$ value \\
\hline \multirow{5}{*}{ Age } & $<20$ & 50 & 6.25 & \\
\hline & $20-24$ & 269 & 33.62 & 0.345 \\
\hline & $25-29$ & 328 & 41.0 & 0.269 \\
\hline & $30-34$ & 104 & 13 & 0.540 \\
\hline & $>35$ & 49 & 6.12 & 0.641 \\
\hline \multirow{2}{*}{ Residence } & Urban & 212 & 26.5 & \\
\hline & Rural & 588 & 73.5 & 0.001 \\
\hline \multirow{2}{*}{ Marital status } & Single & 71 & 8.9 & \\
\hline & Married & 729 & 91.1 & 0.461 \\
\hline \multirow{6}{*}{ Ethnicity } & Bench & 307 & 38.37 & \\
\hline & Keffa & 202 & 25.25 & 0.913 \\
\hline & Amhara & 239 & 29.9 & 0.822 \\
\hline & Oromo & 40 & 5 & 0.322 \\
\hline & Tigra & 7 & 0.87 & 0.252 \\
\hline & Gurage & 5 & 0.62 & 0.716 \\
\hline \multirow{4}{*}{$\begin{array}{l}\text { Educational } \\
\text { status }\end{array}$} & $\begin{array}{l}\text { No formal } \\
\text { education }\end{array}$ & 404 & 50.5 & 0.001 \\
\hline & Primary school & 267 & 33.37 & 0.004 \\
\hline & $\begin{array}{l}\text { Secondary } \\
\text { school }\end{array}$ & 99 & 12.37 & 0.002 \\
\hline & $\begin{array}{l}\text { Diploma and } \\
\text { above }\end{array}$ & 30 & 3.75 & \\
\hline \multirow{5}{*}{ Religion } & Orthodox & 305 & 38 & \\
\hline & Muslim & 158 & 19.75 & 0.632 \\
\hline & Protestant & 330 & 41.25 & 0.461 \\
\hline & Catholic & 5 & 0.62 & 0.357 \\
\hline & $\begin{array}{l}\text { Traditional } \\
\text { beliefs }\end{array}$ & 2 & 0.25 & - \\
\hline \multirow{6}{*}{$\begin{array}{l}\text { Occupational } \\
\text { status }\end{array}$} & $\begin{array}{l}\text { Government } \\
\text { worker }\end{array}$ & 27 & 3.4 & \\
\hline & $\begin{array}{c}\text { Non- } \\
\text { government } \\
\text { worker }\end{array}$ & 190 & 23.8 & 0.376 \\
\hline & Merchant & 60 & 7.5 & 0.420 \\
\hline & Housewife & 344 & 43 & 0.652 \\
\hline & Daily laborer & 123 & 15.4 & 0.516 \\
\hline & Student & 56 & 7 & 0.441 \\
\hline
\end{tabular}

324 (40.5\%) were parity I, 44 (5.5\%) claimed to had abortion, and $73(9.1 \%)$ were unwanted pregnancy, and $320(40 \%)$ mothers had previous facility-based childbirth experience. Five hundred sixty-seven $(70.9 \%)$ of the mothers were prepared for labor and delivery, $704(88 \%)$ of the deliveries were attended by female service provider, 136 (17\%) of the deliveries end up in immediate maternal complication, and 35 (4.4\%) of the deliveries became still birth as shown in (Table 2).

3.3. Maternal Perception of Health Care Service. With respects to maternal perception of facility service availability, $734(91.8 \%)$ of the mothers mentioned the presence of wait- ing area, and $678(84.8 \%)$ mentioned the presence of toilet in the facility. Five hundred thrifty-four $(66.8 \%)$ of the mothers claimed the presence of an attendant throughout delivery, 312 (39\%) of the mothers claimed that they have waited more than 15 minute to be seen by the care provider, $659(82.4 \%)$ of the mothers were informed about the wellbeing of their baby following examination, and care providers measure taken to assure privacy were regarded as "good" by 659 $(82.4 \%)$ of the mothers, summarized in (Table 3 ).

3.4. Maternal Satisfaction with Delivery Care Services. Regarding the three dimensions of satisfaction (component wise satisfaction), technical aspects had the highest median scores followed by communication and interpersonal aspects and environmental aspects. Pertaining to the overall mothers' satisfaction, $506(63.25 \%)$ of the mothers were satisfied with the overall service provided. Mothers were asked whether they would come again and recommend others to utilize facilitybased childbirth care service; more than $88 \%$ of the mothers mention that they would come again and 95\% of mothers claimed to recommend others to deliver at the public health centers (Table 4).

3.5. Factors Associated with Maternal Satisfaction with Delivery Care. After adjusting for "fetal outcome," "sex of the attendants," "presence of maternal complication," "being prepared for labor and delivery," "client informed about the wellbeing of the baby," and "status of the pregnancy," four variables, namely, educational status, residence, measure taken to assure privacy, and attending ANC were found to be significant in the final multivariate logistic regression analysis as shown in (Table 5). Mothers with no formal education and mothers with secondary school were 3.6 and 1.6 times, respectively, more likely to be satisfied by the overall delivery service provided than mothers with educational status diploma and above $(\mathrm{AOR}=3.69 ; 95 \% \mathrm{CI}(1.99,7.91)$ and $\mathrm{AOR}=1.60 ; 95 \% \mathrm{CI}(1.34-2.96)$, respectively). Mothers from rural residence were $\mathrm{AOR}=2.63(95 \% \mathrm{CI}(1.43,5.80))$ times more likely to be satisfied by the overall delivery service provided than those from urban residence. Mothers who regarded measure taken to assure privacy as "good" were $\mathrm{AOR}=3.56(95 \% \mathrm{CI}(1.25,7.41))$ times more likely to be satisfied by the overall delivery service provided than their counterpart. Mothers who fully attended all the WHOrecommended ANC visits were AOR = 6.23 (95\% CI (3.42, 12.87)) more likely to be satisfied by the overall delivery service provided than those who did not.

\section{Discussion}

The present study assessed the level of mothers' satisfaction with delivery service and the associated factors; the study revealed that $63.25 \%$, 95\% CI (60.08\%-66.41\%), of mothers were satisfied with the overall delivery services provided, and this finding is much lower than studies undertaken in Assela Hospital (80.7\%), Wolaita zone (82.9\%), Debre Markos town (81.7\%), and Omo Nada District, Jimma Zone (77\%) [12-15]. Nevertheless, it is higher than studies conducted in Gondar teaching hospital; Northwest Ethiopia 
TABLE 2: The obstetric characteristics of mothers who gave birth in selected public health centers of Bench-Maji Zone, Ethiopia. May 2018. $n=800$

\begin{tabular}{lcccc}
\hline Variables & Response & Frequency & Percent & $P$ value \\
\hline \multirow{4}{*}{ Parity } & 1 & 324 & 40.5 & \\
& $2-4$ & 397 & 49.6 & 0.398 \\
Ever had abortion & Yes & 79 & 9.9 & 0.382 \\
Status of pregnancy & No & 756 & 5.5 & \\
Ever delivered in & Wanted & 727 & 94.5 & 0.269 \\
health facility & Yes & 320 & 40 & \\
Prepared for labor & No & 480 & 60 & 0.509 \\
and delivery & Yes & 567 & 70.9 & 0.071 \\
Sex of attendant & No & 233 & 29.1 & \\
Maternal complication & Female & 704 & 88 & 0.205 \\
immediately & Male & 96 & 12 & \\
Fetal outcome & No & 136 & 17 & 0.187 \\
& Live birth & 765 & 93 & \\
Privacy & Still birth & 35 & 4.4 & 0.097 \\
ANC attended & Good & 513 & 64.1 & \\
& Poor & 287 & 35.9 & 0.001 \\
& Yes & 723 & 90.4 & \\
& No & 77 & 9.6 & 0.001 \\
\hline
\end{tabular}

TABLE 3: Maternal perception of health care service among mothers who gave birth in selected public health centers of Bench-Maji Zone, Ethiopia. May 2018. $n=800$.

\begin{tabular}{lcccc}
\hline Variables & Response & Frequency & Percent & $P$ value \\
\hline Perceived presence & Yes & 734 & 91.8 & \\
of waiting area & No & 66 & 8.2 & 0.901 \\
& Yes & 678 & 84.8 & \\
Presence of toilet & No & 122 & 15.2 & 0.551 \\
Care provider measures & Good & 659 & 82.4 & \\
taken to assure privacy & Not good & 141 & 17.6 & 0.001 \\
Presence of attendant & Yes & 534 & 66.8 & \\
throughout delivery & No & 266 & 33.2 & 0.641 \\
Mother informed about & Yes & 498 & 62.2 & \\
the baby following & No & 302 & 37.8 & 0.407 \\
examination & 15 minute & 488 & 61 & \\
Waiting time to be seen & More & & & \\
by the provider & than & 312 & 39 & 0.312 \\
& 15 minute & & & \\
\hline
\end{tabular}

(31.3\%); Nairobi, Kenya (56\%); and Sri Lanka (48\%) [16-18]. The reason for this discrepancy might be due to socioeconomic characteristic of the study population and the type of facility studied and could also be due to the methodological difference in which we used a threshhold demarcation formula to set the cutoff point for satisfaction.
TABLE 4: Median satisfaction score of the three dimensions of satisfactions among mothers gave birth in selected public health centers of Bench-Maji Zone, Ethiopia. May 2018.

\begin{tabular}{ll}
\hline Dimensions & Median \\
\hline $\begin{array}{l}\text { Technical aspects } \\
\text { Level of satisfaction with pain management }\end{array}$ & 5 \\
$\begin{array}{l}\text { Level of satisfaction with support given during } \\
\text { labor \& delivery }\end{array}$ & 4 \\
$\begin{array}{l}\text { Level of satisfaction with care given to newborn } \\
\text { Level of satisfaction with time given by providers }\end{array}$ & 5 \\
$\begin{array}{l}\text { Level of satisfaction with continuity of care } \\
\text { Level of satisfaction with general care received }\end{array}$ & 5 \\
$\begin{array}{l}\text { Communication and interpersonal aspects } \\
\text { Level of satisfaction with explanation }\end{array}$ & 5 \\
$\begin{array}{l}\text { before procedures } \\
\text { Level of satisfaction with promptness of response }\end{array}$ & 5 \\
$\begin{array}{l}\text { Level of satisfaction with supportiveness of staff } \\
\text { Level of satisfaction with allowing socials to be together }\end{array}$ & 5 \\
$\begin{array}{l}\text { Level of satisfaction with respect } \\
\text { Environmental aspects }\end{array}$ & 4 \\
$\begin{array}{l}\text { Level of satisfaction with easily getting maternity } \\
\text { ward starting from the gate }\end{array}$ & 4 \\
$\begin{array}{l}\text { Level of satisfaction with maternity ward's toilets, } \\
\text { hand washing and shower. }\end{array}$ & 4 \\
$\begin{array}{l}\text { Level of satisfaction with cleanness of the ward } \\
\text { Level of satisfaction with infrastructures like } \\
\text { electricity, water }\end{array}$ & 3 \\
$\begin{array}{l}\text { Level of satisfaction with easily getting maternity ward } \\
\text { starting from the gate }\end{array}$ & 5 \\
\hline & 4 \\
\hline
\end{tabular}

When it comes to component-wise satisfaction, technical aspects had the highest median scores followed by communication and interpersonal aspects and environmental aspects. In contrary to this finding, the study conducted in Sri Lanka claimed a lower level of satisfaction with technical aspects compared to any another components [18]. This disparity could be due to study setting difference in which our study was conducted among health centers; higher satisfaction with technical aspect at health centers than hospitals might imply work fatigue as a health care provider at a hospital level attends to many deliveries in a day than one working at health-center level because of high client flow. Environmental aspect had the lowest median score than any other components, and this is consistent with the study undertaken in South Ethiopia and contradicts with the study conducted in India and Bangladesh - in which a relatively high proportion of clients are satisfied with environmental aspect $[19,20]$. This could be explained as hospitals are relatively more equipped with facility infrastructures like toilet, water, and electricity compared with health centers.

The current study evidenced a reciprocal relationship between educational status and mother satisfaction; mothers with secondary school and lower educational status were 
TABLE 5: Factors significantly associated with overall mothers' satisfaction in multivariate logistic regression, Bench-Maji Zone, Ethiopia. May 2018.

\begin{tabular}{|c|c|c|c|c|c|}
\hline \multirow[b]{2}{*}{ Variables } & \multicolumn{2}{|c|}{ Level of satisfaction } & \multirow[b]{2}{*}{ COR (95\% CI) } & \multirow[b]{2}{*}{ AOR (95\% CI) } & \multirow[b]{2}{*}{$P$ value } \\
\hline & $\begin{array}{c}\text { Satisfied } \\
\text { Count (\%) }\end{array}$ & $\begin{array}{c}\text { Dissatisfied } \\
\text { Count (\%) }\end{array}$ & & & \\
\hline \multicolumn{6}{|l|}{ Educational status } \\
\hline No formal education & $317(78.46 \%)$ & $87(21.53 \%)$ & $11.97(5.01-29.43)$ & $3.69(1.99,7.91)$ & 0.001 \\
\hline Primary school & $137(51.31 \%)$ & $130(48.69 \%)$ & $3.46(2.91-7.01)$ & $1.27(1.03,1.94)$ & 0.034 \\
\hline Secondary school & $45(45.45 \%)$ & $54(54.54 \%)$ & $2.73(1.59-6.05)$ & $1.60(1.34-2.96)$ & 0.012 \\
\hline Diploma and above & $7(23.33 \%)$ & $23(76.67 \%)$ & 1 & 1 & \\
\hline \multicolumn{6}{|l|}{ Residence } \\
\hline Urban & $88(46.22 \%)$ & $124(53.78 \%)$ & 1 & 1 & \\
\hline Rural & $418(69.39)$ & $170(30.61 \%)$ & $3.47(1.99-10.14)$ & $2.63(1.43,5.80)$ & 0.001 \\
\hline \multicolumn{6}{|c|}{ Measure taken to assure privacy } \\
\hline Good & $387(75.43 \%)$ & $126(24.57 \%)$ & $4.33(2.77-9.01)$ & $3.56(1.25,7.41)$ & 0.001 \\
\hline Poor & $119(41.46 \%)$ & $168(58.54 \%)$ & 1 & 1 & \\
\hline \multicolumn{6}{|l|}{ ANC attended } \\
\hline Yes & $435(65 \%)$ & $288(30 \%)$ & 1 & 1 & \\
\hline No & $71(46.75 \%)$ & $6(53.24 \%)$ & $7.83(5.78-19.43)$ & $6.23(3.42,12.87)$ & 0.001 \\
\hline \multicolumn{6}{|l|}{ Fetal outcome } \\
\hline Live birth & $476(62.22)$ & $289(37.78)$ & 1 & 1 & \\
\hline Still birth & $30(85.71 \%)$ & $5(14.29)$ & $3.64(1.07-6.03)$ & $1.27(0.87,29.11)$ & 0.631 \\
\hline \multicolumn{6}{|l|}{ Sex of the attendants } \\
\hline Female & $462(65.62 \%)$ & $242(34.37 \%)$ & 1 & 1 & \\
\hline Male & $44(45.83 \%)$ & $52(54.16 \%)$ & $0.44(0.16-0.71)$ & $0.19(0.01-1.06)$ & 0.701 \\
\hline \multicolumn{6}{|c|}{ Presence of maternal complication } \\
\hline Yes & $75(55.14 \%)$ & $61(44.85 \%)$ & $0.65(0.29,0.9)$ & $0.25(0.11,1.09)$ & 0.167 \\
\hline No & $437(65.22 \%)$ & $233(34.78 \%)$ & 1 & 1 & \\
\hline \multicolumn{6}{|c|}{ Being prepared for labor and delivery } \\
\hline Yes & $386(68.08)$ & $181(31.92 \%)$ & 1 & 1 & \\
\hline No & $120(51.5 \%)$ & $113(48.49 \%)$ & $0.49(0.06,1.04)$ & $1.09(0.24,29.07)$ & 0.408 \\
\hline \multicolumn{6}{|c|}{ Client informed about the wellbeing of the baby } \\
\hline Yes & $314(63.05 \%)$ & $184(36.95 \%)$ & $0.98(0.11,1.52)$ & $0.41(0.21-2.97)$ & 0.091 \\
\hline No & $192(63.58 \%)$ & $110(36.42 \%)$ & 1 & 1 & \\
\hline \multicolumn{6}{|l|}{ Status of the pregnancy } \\
\hline Wanted & $444(61.07 \%)$ & $283(38.93 \%)$ & $0.28(0.18,0.97)$ & $0.45(0.31,2.03)$ & 0.338 \\
\hline Unwanted & $62(84.93 \%)$ & $11(15.07 \%)$ & 1 & 1 & \\
\hline
\end{tabular}

more likely to be satisfied with delivery service than those with diploma and above educational status. This finding is in agreement with the study conducted in Arba Minch, Ethiopia, Tanzania, Ghana, and Zambia [21-24]. Higher satisfaction in low literacy setting might attribute to expectation difference that more educated mothers could have higher expectation since they are aware of the care standards and client rights than less educated mothers.

Mothers from rural residence were AOR $=2.63$ (95\% CI $(1.43,5.80))$ times more likely to be satisfied by the overall delivery service provided as compared to mothers from urban residence. This finding is substantiated by other studies conducted in Addis Abeba, Ethiopia, Tshwane, South Africa, and Brazil, where mothers coming from rural resi- dence were more satisfied than those from urban residence [25-27]. This might be due to the difference in media exposure; mothers from rural residence might have poor media exposure regarding delivery service and have less service expectations compared to their urban counterpart.

The other most important predictor of client satisfaction in this study was mother's perceived measure taken to assure her piracy. Those mothers who regarded measure taken to assure their privacy as "good" were AOR $=3.56(95 \% \mathrm{CI}$ $(1.25,7.41))$ times more likely to be satisfied than their counterpart. Similar finding was suggested by studies conducted in Southern Ethiopia, Northwest Ethiopia, Malawi, and Zambia $[25,28-30]$. This could be explained as privacy is a key requirement for a women in the delivery process. A sense 
of shame is attached to it; hence, inadequate privacy during the procedure increases women's discomfort and diminishes their satisfaction levels.

Mothers who fully attended all the WHO-recommended $\mathrm{ANC}$ visits were $\mathrm{AOR}=6.23(95 \% \mathrm{CI}(3.42,12.87))$ times more likely to be satisfied by the overall delivery service provided than those who did not attend ANC. This finding is similar with study conducted in Gamo Gofa Zone, Ethiopia [21]. This might be for the fact that ANC users get the necessary preventive care and are less likely to encounter pregnancy complications. Moreover, mothers who had attended ANC would have prepared for labor and delivery and may not expect everything from the health facility.

\section{Conclusion}

The overall satisfaction of mothers with childbirth care in public health centers of Bench-Maji Zone is low when compared with other studies. Mothers' educational status, residency, measure taken to assure privacy, and ANC attendance were significantly associated with mothers' satisfaction with overall delivery service provided. Thus, the Ethiopian Federal Ministry of Health and other relevant stakeholders working on enhancing maternal health service should focus on these determinates to improve maternal satisfaction with childbirth care and ultimately reduce maternal mortality and morbidity in the area.

\section{Abbreviation}

AOR: Adjusted odd ratio

ANC: Antenatal care

CI: Confidence intervals

SBA: Skilled birth assistance

SPSS: Statistical Package for Social Scientists

WHO: World Health Organization.

\section{Data Availability}

The datasets collected and analyzed for the current study is available from the corresponding author and can be obtained upon reasonable request.

\section{Conflicts of Interest}

The authors declare that they have no conflict of interests.

\section{Authors' Contributions}

SH initiated the study, developed the tool, supervised the data collection process, and carried out the statistical analysis, interpret the result, and wrote the final paper and manuscript based on the journal criteria. AG and ES made considerable contributions to interpretation of the results and reviewing the manuscript.

\section{Acknowledgments}

The authors would like to thank Mizan-Tepi University for technical support and ethical approval, study participants, and data collectors.

\section{References}

[1] A. Donabedian, "The quality of care. How can it be assessed?," Archives of Pathology \& Laboratory Medicine 1997, vol. 121, no. 11, pp. 1145-1150, 1988.

[2] Health Strategy Implementation Project, "Measurement of patient satisfaction guidelines measurement of patient satisfaction. Irish Society for Quality and Saftey in Health Care," p. 37, 2003, September 2019, https://www.lenus.ie/handle/ $10147 / 43559 /$.

[3] I. H. Reerink and R. Sauerborn, "Quality of primary health care in developing countries: recent experiences and future directions," International Journal for Quality in Health Care, vol. 8, no. 2, pp. 131-139, 1996.

[4] Z. Dettrick, S. Firth, and E. Jimenez Soto, "Do strategies to improve quality of maternal and child health care in lower and middle income countries lead to improved outcomes? A review of the evidence," Plos One, vol. 8, no. 12, article e83070, 2013.

[5] "WHO j skilled attendants at birthWHOSeptember 2019, https://www.who.int/gho/maternal_health/mortality/ maternal_mortality_text/en/.

[6] W. R. Alliance, Respectful maternity care: the universal rights of childbearing women, White Ribbon Alliance, Washington, DC, 2012.

[7] World Health Organization (WHO), Making Pregnancy Safer: The Critical Role of the Skilled Attendant: A Joint Statement by WHO, ICM, FIGO, World Health Organization (WHO), Geneva, Switzerland, 2004.

[8] F. Chemir, F. Alemseged, and D. Workneh, "Satisfaction with focused antenatal care service and associated factors among pregnant women attending focused antenatal care at health centers in Jimma town, Jimma zone, South West Ethiopia; a facility based cross-sectional study triangulated with qualitative study," BMC Research Notes, vol. 7, no. 1, article 164, 2014.

[9] I. Hildingsson, J. E. Thomas, R. E. Olofsson, and A. Nystedt, "Still Behind the Glass Wall? Swedish Fathers' Satisfaction With Postnatal Care," Journal of Obstetric, Gynecologic, \& Neonatal Nursing, vol. 38, no. 3, pp. 280-289, 2009.

[10] B. Parker, Unhappy consciousness: recognition and reification in Victorian fiction, Columbia University, 2014.

[11] Mizan-Tepi University Teaching HospitalJuly 2018, https:// www.mizantepiuniversity.net/about-us.html.

[12] R. A. Mesfin Tafa, "Maternal satisfaction with the delivery services in Assela Hospital, Arsi zone, Oromia region, Ethiopia,2013," Gynecology \& Obstetrics, vol. 4, no. 12, 2014.

[13] B. Yohannes, M. Tarekegn, and W. Paulos, "Mothers' Utilization of antenatal care and their satisfaction with delivery services in selected public health facilities of Wolaita Zone, Southern Ethiopia," International Journal of Scientific \& Technology Research, vol. 2, no. 2, 2013.

[14] K. Bitew, M. Ayichiluhm, and K. Yimam, "Maternal satisfaction on delivery service and its associated factors among mothers who gave birth in public health facilities of Debre 
Markos Town, Northwest Ethiopia," BioMed Research International, vol. 2015, Article ID 460767, 6 pages, 2015.

[15] B. Haile Tadesse, "Mothers' satisfaction with institutional delivery service in public health facilities of Omo Nada district, Jimma zone," Clinical Medicine Research, vol. 6, no. 1, p. 23, 2017.

[16] K. T. Gashaye, A. T. Tsegaye, G. Shiferaw, A. G. Worku, and S. M. Abebe, "Client satisfaction with existing labor and delivery care and associated factors among mothers who gave birth in university of Gondar teaching hospital; Northwest Ethiopia: Institution based cross-sectional study," PLoS One, vol. 14, no. 2, article e0210693, 2019.

[17] E. S. Bazant and M. A. Koenig, "Women's satisfaction with delivery care in Nairobi's informal settlements," International Journal for Quality in Health Care, vol. 21, no. 2, pp. 79-86, 2009.

[18] U. Senarath, D. N. Fernando, and I. Rodrigo, "Factors determining client satisfaction with hospital-based perinatal care in Sri Lanka," Tropical Medicine \& International Health, vol. 11, no. 9, pp. 1442-1451, 2006.

[19] A. Hasan, "Patient satisfaction with $\mathrm{MCH}$ services among mothers attending the $\mathrm{MCH}$ training institute in Dhaka, Bangladesh," Masters thesis. Mahidol University, Faculty of Graduate Studies, 2007.

[20] A. George, "Quality of reproductive care in private hospitals in Andhra Pradesh. Women's perception," Economic and Political Weekly, vol. 37, pp. 1686-1692, 2002.

[21] Z. Dewana, T. Fikadu, A. G/ Mariam, and M. Abdulahi, "Client perspective assessment of women's satisfaction towards labour and delivery care service in public health facilities at Arba Minch town and the surrounding district, Gamo Gofa zone, south Ethiopia," Reproductive Health, vol. 13, no. 1, article 11, 2016.

[22] O. T. Oladapo and M. O. Osiberu, "Do sociodemographic characteristics of pregnant women determine their perception of antenatal care quality?," Maternal and Child Health Journal, vol. 13, no. 4, pp. 505-511, 2009.

[23] P. Das, M. Basu, T. Tikadar, G. C. Biswas, P. Mridha, and R. Pal, "Client satisfaction on maternal and child health services in rural Bengal," Indian Journal of Community Medicine, vol. 35, no. 4, pp. 478-481, 2010.

[24] D. P. Urassa, A. Carlstedt, L. Nystrom, S. N. Massawe, and G. Lindmark, "Quality assessment of the antenatal program for anaemia in rural Tanzania," International Journal for Quality in Health Care, vol. 14, no. 6, pp. 441-448, 2002.

[25] T. Melese, Y. Gebrehiwot, D. Bisetegne, and D. Habte, “Assessment of client satisfaction in labor and delivery services at a maternity referral hospital in Ethiopia," Pan African Medical Journal, vol. 17, 2014.

[26] S. J. Oosthuizen, A. M. Bergh, R. C. Pattinson, and J. Grimbeek, "It does matter where you come from: mothers' experiences of childbirth in midwife obstetric units, Tshwane, South Africa," Reproductive Health, vol. 14, no. 1, article 151, 2017.

[27] J. Gamble, D. K. Creedy, and B. Teakle, "Women's expectations of maternity services: A community-based survey," Women and Birth, vol. 20, no. 3, pp. 115-120, 2007.

[28] Z. B. Mengesha, G. A. Biks, T. A. Ayele, G. A. Tessema, and D. N. Koye, "Determinants of skilled attendance for delivery in Northwest Ethiopia: a community based nested case control study," BMC Public Health, vol. 13, no. 1, article 130, 2013.
[29] N. MacKeith, O. J. M. Chinganya, Y. Ahmed, and S. F. Murray, "Zambian women's experiences of urban maternity care: results from a community survey in Lusaka," African Journal of Reproductive Health, vol. 7, no. 1, pp. 92-102, 2003.

[30] J. Changole, C. Bandawe, B. Makanani et al., "Patients' satisfaction with reproductive health services at Gogo Chatinkha maternity unit, queen Elizabeth central hospital, Blantyre, Malawi," Malawi Medical Journal, vol. 22, no. 1, pp. 5-9, 2010. 